\title{
¿Qué valores debe incorporar un médico durante su formación?
}

Ignacio Martínez González

Director Gerente de Hospital.

\section{LA ÉTICA DE LA GESTIÓN CLÍNICA}

Durante una buena temporada del año 2006, he estado desarrollando un blog en la revista" Diario Médico" que bajo el título de "Yo quiero ser Jefe" contemplaba la importancia de los directivos médicos y el impacto de los mismos en los servicios de los Hospitales.

Parece por tanto evidente, que ante la defensa tan importante de la gestión que se hace desde el blog, el encargo de mi conferencia versara sobre ello.

Hasta ahí todo bien, pero la pregunta que se me plantea es muy diferente a lo que he intentado contestar desde dicho blog.

Es claro que la función de un jefe es gestionar, pero la pregunta que se me hace... ¿es tan claro que también sea la gestión, de un médico cualquiera en un servicio cualquiera?. Y más aún, ¿esa labor es ética y forma parte de la "Ética Médica?

Pues bien, voy a empezar contestando la pregunta sin rodeos:

SÍ, sin duda sí.

Una vez contestada para que el lector decida si le interesa continuar con la lectura del artículo, pasaré a desarrollar el fundamento de tal afirmación. Y lo haré desarrollando tres apartados, que a diferencia de la conferencia me veo en la necesidad de hacer de manera muy reducida.

Los tres apartados son:

- La ética

- La ética de las empresas

- La ética de la gestión clínica ¿debe incorporarse la gestión clínica como un valor fundamental de la profesión?

\section{- LA ÉTICA}

"No puedo decir que la entiendo, pero sí que puedo observarla".

Pueden observar que es una buena frase, lamentablemente no mía, para eludir una difícil definición.

¿Y porque es difícil definirla? Piensen que en primer lugar la ética varía con el tiempo, y por si esto fuera poco, también varía con el lugar.

¿Que quiere decir esto? Que lo que es ético hoy, quizás no lo será mañana, o no lo fue ayer, y además lo que es ético en nuestro país puede no serlo en otro.

En cuestiones de ámbito general existen numerosos ejemplos que lo ilustran: la ablación del clítoris en ciertos países, la eutanasia en otros, etc.

Ahora, tras estos ejemplos, atrevámonos a poner una sencilla definición: Ética es la disciplina que versa sobre lo bueno y lo malo, sobre el deber y las obligaciones morales.

Aún más, para analizar esas acciones, debemos atender a aspectos cómo el objeto de la acción, el fin, y las circunstancias.

Con estas ideas, pretendo que nos demos cuenta de la complejidad que tienen los juicios éticos y la dificultad de la pregunta inicial acerca de si es ética la gestión clínica o por el contrario, lo ético, consistiría en no incorporar la gestión en ningún juicio clínico.

Hechas estas consideraciones acerca de la ética, consideremos ahora si la ética forma o no forma parte de la actividad diaria de las organizaciones o empresas.

\section{- LA ÉTICA EN LAS EMPRESAS}

Hoy son muchas las empresas que consideran que, sólo el cumplimiento del ordenamiento jurídico, no es suficiente. En todos los países sin excepción, y 
a pesar de su mayor o menor interés en intervenir en la economía, existe una insuficiencia de las leyes para garantizar que las actuaciones de las empresas sean buenas.

$\mathrm{Y}$ es precisamente a partir de ese hecho, que nace la ahora conocida como la "Ética de las empresas".

$\mathrm{Su}$ expresión más evidente, son los habituales códigos éticos de las Compañías, donde se obliga a las personas (trabajadores), en sus comportamientos y se les indica como deben comportarse tanto en lo positivo como en lo negativo.

Visto así, uno puede pensar que rozan la insensatez dichos códigos, pero no es así cuando se vuelve la vista al pasado y se recuerdan décadas pretéritas y los desastres ecológicos producidos por algunas empresas o las discriminaciones sufridas por trabajadores por razones de sexo, edad, etc.

A fecha de hoy son varias las Universidades que incorporan la ética en su programa de estudios y muchos premios, son los que distinguen a las organizaciones que más han destacado en dicho campo.

Pues bien hasta aquí ha llegado, la justificación de porque es necesaria una ética en todos las empresas, algo probablemente superfluo para la medicina, que ya disponía de unos códigos de comportamiento obligado para sus practicantes, mucho antes que cualquier otra profesión.

Pero ¿dentro de ese código debe tener un espacio, la obligación de gestionar adecuadamente los recursos, o no más que en cualquier otra profesión?

Esta pregunta es la que da pié, al tercer y último apartado.

\section{- LA ÉTICA DE LA GESTIÓN CLÍNICA}

Voy a comenzar usando la definición, simple pero muy práctica, que empleo en muchos conversaciones, para la "Gestión". ¿Que es gestionar?

...Gestionar es sacar alcanzar el máximo rendimiento de cada uno de los recursos disponibles.

Detrás de esto hay un profundo significado, que se traduce en que el gestor está obligado, a mirar no solo por algunos sino por todos los recursos que utiliza y a intentar no tan solo que estos logren un nivel aceptable de productividad sino el máximo posible.

¿Estaría por tanto éticamente obligado un médico en su trabajo dentro del hospital o consultorio a cumplir con el deber de la gestión?.

Pues creo que no. Que un deber tan extenso no puede ser habitual, sino tan solo a un directivo (ya fuera médico o no).

Pero ahora pongamos un apellido a la gestión, y limitémosla en su alcance. Llamémosla gestión clínica y tratemos de contestar a la pregunta nuevamente.

¿Qué sería la gestión clínica? ... alcanzar el máximo rendimiento de los recursos clínicos que habitualmente se utilizan en la atención médica.

¿Y cuáles son estos recursos clínicos? Pues todos los recursos físicos y humanos que intervienen en el acto asistencial, tales como las camas, quirófanos, medios diagnósticos, etc, y lo que es más importante, nuestro tiempo y el de las otras personas que participan ya sean enfermeras, técnicos, auxiliares, etc.

Concentrémonos ahora en la importancia de gestionar esos recursos.

El progreso técnico amplia sin cesar las posibilidades de la Medicina, la economía las recorta.

Hoy el dinero es un recurso escaso en nuestros Centros y por lo tanto aplicar bien ese recurso limitado es la clave de la buena gestión. Si el dinero no fuera ese factor limitante de la Medicina a nadie le importaría el costo de la asistencia, no existirían ninguno de los pesados índices que relacionan la atención con el coste de la misma. Pero como lo es, y presumiblemente lo seguirá siendo, es indispensable hacerlo a fin de seguir ampliando las posibilidades de la Medicina.

Por tanto utilizar adecuadamente, cualquiera de los recursos clínicos disponibles, ampliaría las posibilidades de la Medicina y redundaría en unas mayores capacidades diagnósticas y un tratamiento de más calidad de los enfermos.

Pero adentrémonos más aún en la profundidad del uso de los recursos, y en concreto en el del tiempo y del conocimiento.

Dicen los entendidos que "El recurso que más escaso se vuelve en las empresas con éxito no es el dinero sino el tiempo. El conocimiento, y el tiempo necesario para aplicarlo, son la clave del éxito en la atención a los enfermos.

Aora bien, si me pidieran que contestara que recurso será más escaso en el futuro en los Hospitales o Centros de Salud, el dinero o el conocimiento, sin lugar a dudas contestaría que el segundo.

Llegado aquí, recojamos nuevamente la idea de la gestión clínica, y como tal, la necesidad de gestionar todos los recursos clínicos, pero sobre todo los mas escasos, es decir no solo gestionar bien el uso de camas, quirófanos etc., sino el tiempo que dedicamos a los enfermos nosotros y el resto de profesionales que participan en el trabajo, sabiendo además que dicho tiempo está directamente influido por el nivel de conocimiento que poseemos. 
Podemos añadir que, si el conocimiento y el tiempo son realmente importantes a la hora de la gestión, démonos además cuenta, que ambos varían notablemente con la actitud de la persona.

Pues bien, en ello se resume todo lo anterior. La real dificultad de las empresas, que ahora se denominan del conocimiento (y de las cuales los hospitales y centros de salud son los máximos exponentes), son la gestión de las actitudes y de las aptitudes.

Llegado aquí, ya tenemos todos los ingredientes para contestar a la "pregunta" ¿debe ser parte de la ética médica la gestión clínica?

Sí, sin ninguna duda.

- Sí, porque es parte del compromiso que tenemos con la empresa, el uso eficiente de los recursos. Y ello obliga a todos los que realizan su actividad por cuenta ajena.
- Sí, porque es la forma de ampliar las posibilidades de la Medicina, y esto obliga a todos, sanitarios o no sanitarios.

- Y sí, fundamentalmente porque es nuestro compromiso con el enfermo: atenderle.

$\mathrm{Y}$ todo ello, solo podremos hacerlo, en un entorno de recursos escasos, alcanzando el máximo rendimiento de todo aquello que utilizamos, ya sea nuestro tiempo, conocimiento o cualquier otro recurso a nuestra disposición.

Antes de finalizar y por si todavía alguien dudara de que un comportamiento ético precisa una adecuada gestión clínica, dejo una pregunta en el aire para los escépticos. ¿Sería ético no poder tratar a un enfermo a causa de haber utilizado mal previamente los recursos que necesitamos para hacerlo? 